\title{
Does Child Sex Moderate Vulnerability to Postpartum Risk among Infants of Mothers at Risk for Psychopathology?
}

\author{
Ellen McGinnis and Erika Bocknek \\ Department of Psychiatry \\ University of Michigan \\ Marjorie Beeghly \\ Wayne State University \\ Katherine L. Rosenblum and Maria Muzik \\ Department of Psychiatry \\ University of Michigan
}

\begin{abstract}
Early childhood behavior problems may indicate risk for subsequent psychopathology (Shaw, Gilliom, Ingoldsby, \& Nagin, Developmental Psychology, $39,2003,189)$. There is some evidence to suggest that boys and girls may be differentially susceptible to postpartum risk factors that predict problem behaviors in early childhood (Kochanska, Coy, \& Murray, Child Development, 72, 2001, 1091; Martel, Klump, Nigg, Breedlove, \& Sisk, Hormones and Behavior , 55, 2009, 465). The main aim of this study is to examine whether child sex moderates the effect of infant and maternal predictors of toddler problem behaviors in a unique sample of high-risk mother-child dyads. Analyses were based on data collected for 198 mother-child dyads (52\% male offspring) followed longitudinally from birth to 18 months. Maternal and infant variables, including maternal PTSD and depression symptoms, maternal maltreatment history, observed maternal parenting quality, demographic risk, and infant negative emotionality and night wak-
\end{abstract}

Correspondence should be sent to Maria Muzik, Department of Psychiatry, University of Michigan, 4250 Plymouth Rd, Ann Arbor, MI, USA. E-mail: muzik@med.umich.edu 
ing, were used to predict toddler behavior problems. Although boys and girls displayed similar levels of total problem behaviors at 18 months overall, the specific set of infant and maternal variables that predicted toddler problems varied by child sex. The significant predictor for boys was maternal PTSD symptoms, whereas significant predictors for girls were infant negative emotionality and sleep problems. Results suggest that sex-differentiated transmission of risk can be identified as early as 18 months postpartum. These differences suggest a gender-specific biological sensitivity to maternal psychopathology, or alternatively, a gender-specific reporting bias among mothers with childhood maltreatment histories.

The passing of maternal vulnerability to offspring has been termed the "intergenerational transmission of risk" (Bifulco et al., 2002) and involves the passing of predisposed genetic risk as well as the exposure to particular risky pre- or postpartum environments that shapes offspring functionality (for reviews see Champagne \& Curley, 2009; Glover, 2011; Wan \& Green, 2009). Recent animal research proposes that epigenetics underlies sex-specific sensitivity to postpartum environmental influences subsequently shaping differential sensitivity to life stress for males and females (Hodes, 2013). In humans, there is emerging evidence that boys may be more susceptible to maternal risk earlier in development compared to girls (Blatt-Eisengart, Drabick, Monahan, \& Steinberg, 2009; Hammen, Hazel, Brennan, \& Najman, 2012; Shaw \& Vondra, 1995), while girls appear to show sensitivity to stressful environments later in life (Hammen et al., 2012). Studies that do find differential susceptibility in boys versus girls speculate that child sex may be linked to slower maturation rates in boys (Kochanska, Coy, \& Murray, 2001; Martel, Klump, Nigg, Breedlove, \& Sisk, 2009) creating a longer period of early sensitivity, thereby permitting boys to be more impacted by risk in postpartum. Postpartum risk may include exposure to risky parenting and parental expectations, shown to be differentiated by the sex of offspring as well (Blatt-Eisengart et al., 2009; Hammen et al., 2012; Shaw \& Vondra, 1995). However, these results are far from consistent; most risk transmission studies omit gender analyses altogether, and others reveal null results (Essex, Klein, Cho, \& Kalin, 2002; McKee et al., 2007). Inconsistent findings may be partially explained by varied methodological and analytic approaches. For instance, the data specifying which early maternal risk exposures may interact with child sex to create adverse developmental outcomes are highly varied, with studies proposing maternal depression, or parenting behaviors, or attachment, or maternal age as culprits (Blatt-Eisengart et al., 2009; Carter, Garrity-Rokous, Chazan-Cohen, Little, \& Briggs-Gowan, 2001; 
Hammen et al., 2012; Shaw \& Vondra, 1995). Other data suggest that infant risk factors, rather than maternal risk, are salient to compromised developmental trajectories (Fox, 2004; Gregory \& Sadeh, 2012; Mathiesen, Sanson, Stoolmiller, \& Karevold, 2009; Sanson, Smart, Prior, \& Oberklaid, 1993). However, child sex has not been fully explored as a moderator in this literature.

In this study, we aim to elucidate some of the sex-specific sensitivity to early risk constellations, both maternal and infant-specific, in predicting the unfolding of children's subsequent poor developmental outcomes, namely early onset childhood behavior problems. Specifically, we explore the role of child sex as a moderator of the unique contribution of several established maternal (maternal childhood maltreatment history, postpartum depression and PTSD, observed parenting), and infant (negative emotionality and poor sleep regulation) risk factors on toddlers' behavior problems at 18 months of age.

\section{INTERGENERATIONAL RISK FACTORS IN THE POSTPARTUM PERIOD}

A history of childhood maltreatment increases a mother's risk for developing PTSD (Yehuda, Halligan, \& Grossman, 2001) and depression (Herrenkohl, Hong, Klika, Herrenkohl, \& Russo, 2012). In turn, mothers with a history of childhood maltreatment are more likely to have children who are less responsive (Van Ee, Kleber, \& Mooren, 2012), and more likely to exhibit internalizing and externalizing symptoms (Valentino, Berkowitz, \& Stover, 2010) (particularly when mothers' trauma history is severe). The negative associations between maternal depression and child well-being are fairly robust and well documented (for a review, see Beardslee, Gladstone, \& O'Connor, 2011; McLearn, Minkovitz, Strobino, Marks, \& Hou, 2006; Petterson \& Albers, 2001), but less is known regarding the effect of maternal PTSD on children's socio-emotional functioning (Al-Turkait \& Ohaeri, 2008; Selimbasic, Sinanovic, \& Avdibegovic, 2012; Van Ee et al., 2012). Explanations of how maternal psychopathology directly leads to elevated child behavior problems vary. Some posit that this association stems from an increased familial disposition to emotional problems (Kovacs, Devlin, Pollock, Richards, \& Mukerji, 1997), whereas others attribute this association to maternal negative perception bias (Chilcoat \& Breslau, 1997). However, the effects of maternal history of maltreatment, depression, and PTSD have yet to be studied together in one sample, which may help us better understand the unique effects of each and their direct effects on child behaviors. 
Suboptimal caregiving, often comorbid with parental psychological distress, low socioeconomic status, low support, and dysregulated physiology, has also been associated with child behavior problems (Buist, 1998; Calkins, Propper, \& Mills-Koonce, 2013). In at-risk populations, negative parenting during infancy is linked to children's behavior problems (Easterbrooks, Bureau, \& Lyons-Ruth, 2012) and positive parenting to resilience (Williams et al., 2009). This suggests that the quality of caregiving during early development is linked to the child's ability to adapt to adversity (Armstrong, Birnie-Lefcovitch, \& Ungar, 2005). There is also some evidence that parenting plays a mediating role in the association between maternal trauma history or psychopathology and child behavior problems (Harold et al., 2011; Martinez-Torteya et al., 2013; Serbin \& Karp, 2004). Other studies find that although both factors can yield negative consequences for the child, parenting is not necessarily a mediator of parental distress (Hofferth, Pleck, \& Vesely, 2012; Loeber, Hipwell, Battista, Sembower, \& Stouthamer-Loeber, 2009).

In addition to maternal and caregiving risk, child outcomes may be impaired from genetic trait variations that contribute to children's temperament and self-regulatory capacities (DiLalla, Mullineaux, \& Biebl, 2012; Nigg \& Goldsmith, 1998). Self-regulation refers to infants' capacity to control internal states of arousal and negative emotionality during the day, captured in temperamental measures, and at night, as the ability to fall asleep after night waking (Goodlin-Jones, Burnham, Gaylor, \& Anders, 2001). A growing literature suggests that several markers of selfregulation shape infants' developmental and adjustment outcomes (including both internalizing and externalizing symptoms) and that these effects persist into adolescence and adulthood (Causadias, Salvatore, \& Sroufe, 2012). For instance, across community samples, having a difficult or emotionally reactive temperament in infancy robustly predicts problem behaviors later in childhood (Fox, 2004; Gartstein, Putnam, \& Rothbart, 2012; Sanson et al., 1993). Additionally, although understudied, infants' sleep problems are also linked to heightened difficulty in early adaptability and rhythmicity (Spruyt et al., 2008). Night awakenings specifically, termed "self-soothing capacity" by some (Anders \& Keener, 1985), also have been correlated with difficult temperament and heightened risk for developmental delays (for a review see Schwichtenberg \& Goodlin-Jones, 2010). In recent research, night awakenings have been examined as a predictor of childhood problem behaviors (for a review see Gregory \& Sadeh, 2012) and have been associated with maternal-infant bonding problems (Hairston et al., 2011), pediatric anxiety (Forbes et al., 2008), and increased risk for ADHD in later childhood (Cortese, Faraone, Konofal, \& Lecendreux, 2009). 
Overall, this literature suggests there is evidence for the intergenerational (mother-to-infant) transmission of risk, which is associated with a maternal history of maltreatment, postpartum psychopathology, suboptimal parenting, and infant self-regulatory difficulties. Although some work is emerging on the pathways by which this risk may be transmitted (Bifulco et al., 2002; Buist, 1998; Martinez-Torteya et al., 2013), a potentially critical variable (i.e., the role of child sex) that may modify the trajectories of risk transmission has been mainly neglected in current developmental literature. This is puzzling given reported sex differences in reactivity to stressors (Hammen, 2005), early emotional, social, and behavioral maturation (Chung \& Auger, 2013; Davies, Segalowitz, \& Gavin, 2004; Bouchard, Trudeau, Sutton, Boudreault, \& Deneault, 2009; Kochanska et al., 2001), and parental socialization practices (Blatt-Eisengart et al., 2009). Our study attempts to fill this gap in the literature, by specifically evaluating whether child sex differentially alters the associations between early maternal and infant-specific risk factors and toddlers' behavioral problems at 18 months of age.

\section{SEX DIFFERENCES IN PRECURSORS TO CHILD PROBLEM BEHAVIORS}

There is an abundance of studies on child sex and problem behaviors; however, in these studies, child sex is either treated as a control variable (Bagner, Pettit, Lewinsohn, \& Seeley, 2010) or as an independent variable showing, for example, that boys have more externalizing versus internalizing problems (Miner \& Clarke-Stewart, 2008; Keiley, Lofthouse, Bates, Dodge, \& Pettit, 2003; Lunkenheimer, Olson, Hollenstein, Sameroff \& Winter, 2011). Studies comparing gender-specific trajectories of problem behaviors in the first years of life that are based on common risk constellations (both maternal and child-specific) are far less common, but evidence suggesting that maternal psychopathology and caregiving affect boys and girls differently during early development have been accumulating over the years (Blatt-Eisengart et al., 2009; Capaldi, Pears, Kerr, Owen, \& Kim, 2012; Carter et al., 2001; Hammen, Hazel, Brennan, and Najman, 2012; Shaw \& Vondra, 1995). Notably, many of these sex differences were discovered post hoc, such as Hammen (2012) who conducted analyses on a two-group model (by sex) without a priori hypotheses due to poor goodness of fit statistics with the full sample. Other studies explore gender moderation of maternal risk and report null results (Essex et al., 2002; McKee et al., 2007). For instance, although Essex et al. (2002) found that maternal-reported stress during the first year postpar- 
tum was associated with increased child stress hormones (afternoon basal cortisol levels), there was not a significant interaction between maternal stress and child sex on child cortisol. McKee et al. (2007) found that child sex did not moderate the effect of harsh discipline on subsequent behavior problems. Additionally, although many publications explore intergenerational risk, few actually examine pathways by child sex, and it is difficult to tell whether gender moderation is not reported due to a lack of exploration, or null findings. Consequently, the proportion and strength of evidence demonstrating gender moderation of risk transmission remains unclear based on current literature.

The few studies with significant findings on differential sex-specific risk susceptibility deserve more detailed exploration. In their study of 100 lowincome families, Shaw and Vondra (1995) found that mothers' depressive symptoms and lesser involvement during mother-child interaction predicted more behavior problems for boys, but not for girls, at age three. In contrast, difficult infant temperament across the first 2 years of life predicted more behavior problems at age 3 for girls, but not for boys. Interpreting their findings, the study authors proposed that when caregivers are depressed and unresponsive, boys may try to elicit responsiveness through externalizing behaviors, whereas for girls, externalizing behaviors are less tolerated by parents and thus girls may find alternative, potentially more adaptive strategies to cope. Another study on sex-specific pathways investigated 69 mother-child dyads and found that prenatal, postpartum, and concurrent maternal depression were significantly correlated with higher levels of problem behaviors (both internalizing and externalizing) for boys, but not for girls (Carter et al. (2001). In contrast, poor quality of parenting during the postpartum period was correlated with a higher prevalence of internalizing problems at 30 months for girls, but not for boys. These findings confirm the work by Shaw and Vondra (1995) that boys may be more susceptible than girls to ongoing stress exposure early in life, in such that boys displayed more impairment in self-regulatory outcomes compared to girls when exposed to chronic maternal depression from prenatal to across the first years postpartum. In contrast, for girls, while less consistent, research findings suggest that difficult temperament in infancy may be a risk factor for behavior problems later in childhood. While both of these studies found sex-specific risk factors associated with behavior problems in early childhood, sample sizes were modest and no analytic tests were conducted to demonstrate the statistical significance of these sex differences.

Studies on larger samples of transgenerational risk demonstrate statistical differences between male and female models. For instance, in a sample of 705 families, Hammen et al. (2012) found a significant interaction 
between maternal depression in the child's first 5 years of life and child sex such that for boys, having a mother with depression early on predicted greater likelihood of child depression during adolescence, but this was not significant for girls. The authors offered no specific hypothesis or explanation for these findings. Additionally, in a sample of over 1,000 families, Blatt-Eisengart et al. (2009) found that the relationship between externalizing symptoms and maternal depression was most pronounced in boys at 24 months old, but this was not true for girls. These authors suggest that these sex differences may be due to differences in the socialization practices parents use for boys and girls, or a greater parental acceptance or reinforcement of early childhood misbehaviors in boys. Comparing models of males and females, Capaldi et al. (2012) found that maternal depression and maternal age significantly predicted both externalizing and internalizing symptoms for boys (accounting for 24 and $40 \%$ variance, respectively), but the same models for girls were not significant (predicting 8 and $17 \%$ variance, respectively) (Capaldi et al., 2012). Differential models based on child sex were not hypothesized a priori and the authors speculated that these sex differences may due to differences in maternal report.

Taken together, this literature suggests that there may be important sex differences in how maternal and infant risk factors affect the development of children's problem behaviors, which deserve further exploration. Furthermore, studies of intergenerational risk transmission in children of atrisk mothers such as mothers with a history of childhood maltreatment are sparse, despite evidence that these mothers show increased rates of postpartum psychopathology, suboptimal parenting, and co-occurring infant regulatory problems (Martinez-Torteya et al., 2013). Therefore, women over-recruited to have a childhood history of maltreatment appear to be an appropriate sample in which to study sex differences in the intergenerational transmission of risk from mother to child.

\section{THE CURRENT STUDY}

This longitudinal study examines the unique contribution of a set of maternal and infant risk factors measured in early postpartum in predicting children's behavior problems at 18 months postpartum, and whether differential risk factors predict child outcomes based on child sex. Following previous work (Blatt-Eisengart et al., 2009; Capaldi et al., 2012; Carter et al., 2001; Hammen, 2005; Shaw \& Vondra, 1995), we hypothesized that maternal reports of toddler problem behaviors would be associated with maternal postpartum risk (psychopathology and suboptimal parenting) for 
boys only, whereas perceived infant regulatory problems, as assessed using maternal reports of difficult temperament and sleep problems, would not be differentially predicted by child sex.

\section{METHOD}

The current analyses were based on data collected for 198 mother-infant dyads enrolled in a larger ongoing longitudinal study, entitled Maternal Anxiety during the Childbearing Years (MACY), which evaluates the impact of mothers' childhood maltreatment exposure on their postpartum mental health, parenting quality, and their children's socio-emotional development from 6 weeks to 18 months postpartum (see Muzik et al., 2013 for more details).

\section{Participants}

The current study over-recruited for maternal history of maltreatment, and therefore, mothers in the sample are at higher risk for experiencing postpartum mental health problems than mothers recruited from an unselected community sample (Buist, 1998). This recruitment strategy allows us to model and evaluate the intergenerational transmission of risk. Of the 198 mothers, $73.7 \%$ reported a history of childhood trauma, and 25.5 and $21.8 \%$ met diagnostic criteria for a PTSD and depression diagnosis at 6 months postpartum, respectively. More than half $(62.8 \%)$ were Caucasian, $23.6 \%$ were African American, and the remaining $11.2 \%$ were Asian/Pacific Islander, Latina, or biracial. At 6 months postpartum, nearly a fourth $(23.8 \%)$ were not married or living with an intimate partner. Regarding level of maternal education, $14.4 \%$ had a high school diploma or GED, $31.4 \%$ had completed some college (associate's or vocational degree), $29.8 \%$ had a bachelor's degree, and $24.4 \%$ had a master's or doctoral degree. Participants' family income was bimodal such that $30.7 \%$ reported less than $\$ 25,000$ per year, and $20 \%$ reported an income of more than $\$ 100,000$ per year. Approximately half $(52.5 \%)$ of the infants in the sample were male.

Women were recruited for the MACY study in one of two ways: $61 \%$ $(n=121)$ as part of a postpartum follow-up to a study on the prenatal effects of PTSD on childbearing (see Seng, Low, Sperlich, Ronis, \& Liberzon, 2009, for further details), and $39 \%(n=77)$ as part of a postpartum community recruitment effort within the same area via flyers. Eligible women were nonpsychiatrically referred, 18 years of age or older, and English speaking. Exclusion criteria included mothers' self-report of 
abusing drugs during pregnancy, maternal bipolar or psychotic illness, child premature birth ( $<37$ weeks gestation), and child developmental disability or severe illness. The University Institutional Review Board approved this study, and all recruited women provided written informed consent for their participation.

\section{Procedures}

For the current analysis, the dependent variables were toddlers' internalizing and externalizing behavior problems as assessed via maternal report on Achenbach's Child Behavior Checklist (CBCL/1.5-5, Achenbach \& Rescorla, 2000) during a telephone survey at 18 months postpartum. Predictor variables included maternal self-reports of their history of childhood maltreatment obtained during a telephone survey at 4 months postpartum, and self-reports of their PTSD and depression symptoms, their infant's negative emotionality and night waking, and family demographics were assessed during a home visit at 6 months postpartum. Observed maternal positive parenting (i.e., engagement with the infant) was also assessed from videotaped mother-child interactions at the 6month home visits.

\section{Measures}

\section{Maternal history of child maltreatment}

At 4 months postpartum, mothers reported on their childhood trauma experiences using the 28-item Child Trauma Questionnaire (CTQ) (Bernstein \& Fink, 1998). Mothers rated each item using a 5-point Likert scale yielding five scales of Emotional Abuse, Physical Abuse, Sexual Abuse, Physical Neglect, and Emotional Neglect. In the present analyses, the sum of all abuse and neglect scales was evaluated $(\alpha=.95)$.

\section{Maternal PTSD symptoms}

Post-traumatic stress disorder (PTSD) symptoms were assessed using the National Women's Study PTSD Module (Resnick, Kilpatrick, Dansky, Saunders, \& Best, 1993) at 6 months postpartum. This scale measures all 17 symptoms of PTSD and yields both a dichotomous diagnosis and a continuous symptom count score $(\alpha=.875)$. PTSD diagnoses were created using DSM-IV criteria of having at least one symptom of re-experiencing, three symptoms of avoidance, and two symptoms of hyperarousal, in concordance with previous literature (Resnick et al., 1993). 


\section{Maternal depression symptoms}

Mothers' depression symptoms were assessed using the 35-item Postpartum Depression Screening Scale (PPDS, Beck \& Gable, 2000) at 6 months postpartum. Compared to the SCID diagnosis of major depression, the PPDS has a sensitivity of 0.78 , a specificity of 0.99 . Maternal depression symptom count was used in the current analyses $(\alpha=.96)$. Depression diagnoses were determined using a cut score of 80 in concordance with previous literature (Beck \& Gable, 2000).

\section{Observed maternal parenting engagement}

Mothers' engagement with the infant was evaluated from videotapes of mother-infant interaction at the 6-month home visits (two visits separated by 1 week). Maternal engagement was rated during four interactive contexts varying in level of challenge: two 5-min free-play tasks (one at each home visit) and two 3-min teaching tasks (conducted after free play in first home visit).

Mothers' level of engagement with the infant was scored during each context using a 5-point Likert scale, which ranged from 1 (completely or almost completely disengaged, or negatively engaged) to 5 (very high positive engagement) using the Maternal Engagement/Disengagement Scale from the MACY Infant-Parent Coding System (MIPCS; Earls, Muzik, \& Beeghly, 2009) developed for this study. This scale covers the full spectrum of interactive experience in one scale: on the high end (5), it lists high levels of engagement with positive affect; in the middle score range (3), moderate levels of engagement with neutral affect, and on the low range (1), interactive avoidance and flat affect. Mother's rejecting/hostile/ abusive and frightened/frightening behaviors were coded on separate scales; however, frequency distributions of these scales were extremely skewed, and thus, these scales were not used for subsequent analyses. Several scales included in the MIPCS were adapted from those in several extant mother-infant coding systems (e.g., Beeghly, 2006; Dayton et al., 2010; Feldman, 1998). Trained reliable coders masked to maternal maltreatment history and other study variables scored the videotaped motherinfant interaction protocols. To assess intercoder reliability, 40 randomly selected videotapes $(21 \%)$ were independently rescored. Intercoder reliability was very good for engagement ratings made in each context (free-play ICC $=.85$; teaching ICC $=.71$ ). Because ratings of maternal engagement were highly correlated across contexts (mean $r=.656, p<.001$ ), the means of the two free-play scores and means of the two teaching tasks scores were summed to create a single composite variable. 


\section{Cumulative demographic risk}

Following Sameroff, Seifer, \& McDonough, (2004), a cumulative demographic risk index was created by summing the following dichotomized $(1=$ present, $0=$ absent $)$ risk indicators: young maternal age $(\leq 22$ years at 6 months postpartum), incomplete education (a high school diploma or GED only), non-Caucasian race/ethnicity, not having an intimate partner living in the household, and total family income below the federal poverty line $(\leq \$ 15,000)$. In the current sample, scores on the demographic risk index ranged from 0 to $5(M=1.13, S D=1.41)$.

\section{Infant negative emotionality}

Mothers reported on their infant's temperament at the 6 months postpartum using the 20-item Emotionality, Activity, and Sociability (EAS) Scale (Buss \& Plomin, 1975). The Emotionality subscale assesses negative emotionality and was evaluated in this study because it has been linked to later child behavior problems in prior research (Rende, 1993) and has good internal reliability in the current sample $(\alpha=.73)$.

\section{Infant sleep regulation}

Mothers reported on their infants' current sleep problems at the 6month home visit using the 51-item Sleep Habits Questionnaire (Seifer, Dickstein, Spirito, \& Owens-Stively, 1996). For the current analyses, the Night Waking subscale was used as a measure of infant sleep regulation, which addresses frequency of the child waking during the night $(\alpha=.70)$.

\section{Toddler problem behaviors}

At the 18-month phone survey, mothers reported on their toddlers' problem behaviors using the Child Behavior Checklist (CBCL/1.5-5, Achenbach \& Rescorla, 2000). Scoring yields two broadband scores: internalizing and externalizing, which have high internal reliability in the current sample $(\alpha=.77$, and .88 , respectively).

\section{Missing data}

Of the 198 dyads who completed a 6 month home visit, $70(35 \%)$ participants dropped out between the 6- and 18-month time points and thus had missing infant outcome data. Fifty-five percent of these participants could not be reached despite several attempts by research assistants by phone 
and mail, $24 \%$ no longer wished to participate, and $11 \%$ moved away. Additionally, some participants had missing data on specific predictor variables ranging from 3\% (parenting codes) to $21 \%$ (PTSD and depression symptoms). Results of thorough nonresponse analyses demonstrated that participants with missing data did not differ from those without missing data on any predictor variable, with one exception: Participants who dropped out had higher cumulative demographic risk scores $(p<.05)$, which is commonly observed in longitudinal samples (Bocknek, BrophyHerb, \& Banerjee, 2009). Data were considered missing at random (MAR) because attrition was related only to a common mechanism, not to a participant's status on predictor and/or outcome variables of interest; data were not missing completely at random (MCAR) as a possible mechanism for nonresponse is known and missing data are not considered nonignorable (NI) (Acock, 2005; Schafer \& Graham, 2002). Missing data were imputed via the Expectation Maximization (EM) algorithm (Dempster, Laird, \& Rubin, 1977), which is appropriate when data are MAR. This strategy is also appropriate for the amount of missing data in the current study and is ideal for use in latent model analyses (Graham, 2012; Newman, 2003). Missing data on key variables were imputed using the same variable at the 4-month time point in lieu of 6 months (i.e., PTSD symptoms reported at 4 months), or when unavailable, imputation was informed by significantly correlated variables at 4 or 6 months not used in the current study's main analyses.

\section{Statistical analyses}

Before evaluating the primary hypotheses of the study, preliminary univariate and bivariate analyses were conducted using SPSS version 19 IBM SPSS, Armonk, NY. Univariate statistics were conducted to calculate descriptive statistics and evaluate the distributional properties of the study variables. Independent sample $t$-tests were used to determine whether there were preexisting sex differences in any of the maternal or child risk factors or in the child behavior outcome variables. Correlations were also conducted to examine relationships among the study variables. The possibility of multicollinearity among predictors was evaluated using variance inflation factor (VIF) scores.

Our hypotheses were evaluated by conducting structural equation modeling (SEM) using LISREL 8.80 Scientific Software International, Inc., Skokie, IL, USA. Structural equation modeling includes several important advantages for the current study: (1) SEM allows us to consider global fit statistics of the model as well as individual, linear associations between variables, (2) SEM models error variance, an issue common in develop- 
mental studies with parent-report measures, and (3) SEM is an approach ideal for testing categorical moderation (Tomarken \& Waller, 2005). In addition, although internalizing and externalizing behaviors are likely to be highly correlated among toddlers and are highly correlated in our current sample as well, they do not demonstrate total overlap. Therefore, the approach in the current study includes a measurement model that is true to this phenomenon.

Structural equation modeling was used as the primary analytic strategy despite our sample size of 198. Although statistical experts (MacCallum \& Austin, 2000) agree that there are no universal lower bound guidelines for sample size, multiple researchers (Barrett, 2007; Tanaka, 1987; Tomarken \& Waller, 2005) suggest the general range of $N=200$ is sufficient, and Boomsma (1983) and Gebring and Anderson (1985) have indicated $N=100$ as sufficient in the case of maximum likelihood estimation (as was used in the current study) as a strong lower bound based on Monte Carlo simulation (Boomsma, 1983; Gebring \& Anderson, 1985). Therefore, an SEM approach is justified in the current study $(N=198)$.

Child internalizing and externalizing problems were combined into a latent factor of total toddler problems, and the squared multiple correlations are represented. Acceptability of fit indices are based on published and commonly used criteria (Hu \& Bentler, 1999). We evaluated the full (single-group) model $(N=198)$ as well as a two-group model comparing boys $(n=104)$ and girls $(n=94)$, to evaluate the moderating effect of sex on the association between postpartum predictors (maternal and infant) and the 18-month dependent variable (internalizing and externalizing problem behaviors) with the full set of imputed data. Significant $(t>1.96)$ standardized path coefficients $(\beta)$ are bolded in the figures. Testing moderation via a two-group model in SEM is a classic approach when the moderator is categorical, and especially when it is dichotomous, as is the case in the current model where the moderator is child gender (Brody et al., 2006; Fabrigar \& Wegener, 2014; Iacobucci, 2010), and this is a strategy we have successfully used in other studies (*BLINDED*).

\section{RESULTS}

\section{Descriptive analyses}

Descriptive statistics for the predictor and dependent variables are presented by child sex in Table 1 . Results of preliminary univariate analyses indicated that all study variables were normally distributed. There were no significant sex differences on any predictor variables or on child Internalizing or Externalizing Problems. Bivariate correlations among the key pre- 
dictor and dependent variables are presented in Table 2. Variance inflation factor scores, used to assess multicollinearity, were under 2, and thus, collinearity among predictor variables was identified as unlikely.

\section{Structural equation model for primary aim}

The primary aim was to investigate which set of maternal and infant predictor variables would show direct associations with toddler behavior problems, and whether predictions would vary by child sex. We used multigroup SEM analyses to compare predictors for boys and girls.

Results of the full model (Figure 1) indicated good model fit $\left(\chi^{2}=6.71\right.$, $d f=6, p=.37 ;$ RMSEA $=.02 ;$ GFI $=.99 ;$ SRMR $=.01)$ and demon-

TABLE 1

Descriptive Statistics for Infant and Maternal Predictor and Toddler Outcome Variables by Child Sex $(N=198)$

\begin{tabular}{|c|c|c|c|c|c|c|}
\hline & \multirow{2}{*}{$\begin{array}{l}\text { Whole sample } \\
\qquad \begin{array}{c}N=198 \\
M(S D)\end{array}\end{array}$} & \multicolumn{5}{|c|}{ Child sex } \\
\hline & & $\begin{array}{c}\text { Boys } n=104 \\
M(S D)\end{array}$ & $\begin{array}{c}\text { Girls } n=94 \\
M(S D)\end{array}$ & $t$ & $d f$ & $p$ \\
\hline \multicolumn{7}{|c|}{ Infant and maternal predictors } \\
\hline $\begin{array}{l}\text { Maternal child } \\
\text { maltreatment } \\
\text { Range: } 25-125\end{array}$ & $44.27(17.16)$ & $42.73(16.17)$ & $45.98(18.13)$ & 1.33 & 196 & .19 \\
\hline $\begin{array}{l}\text { Maternal PTSD } \\
\text { symptoms } \\
\text { Range: } 0-17\end{array}$ & $4.46(4.18)$ & $4.48(3.91)$ & $4.44(4.47)$ & -0.08 & 196 & .93 \\
\hline $\begin{array}{l}\text { Maternal depression } \\
\text { Range: } 35-135\end{array}$ & $64.72(21.26)$ & $64.33(20.87)$ & $65.16(21.79)$ & 0.28 & 196 & .78 \\
\hline $\begin{array}{l}\text { Observed parenting } \\
\text { engagement } \\
\text { Range: } 2-10\end{array}$ & $7.51(0.99)$ & $7.51(1.07)$ & $7.32(1.29)$ & -1.17 & 196 & .24 \\
\hline $\begin{array}{l}\text { Cumulative } \\
\text { demographic risk } \\
\text { Range: } 1-5\end{array}$ & $1.10(1.39)$ & $1.08(1.45)$ & $1.12(1.34)$ & 0.18 & 196 & .86 \\
\hline $\begin{array}{l}\text { Infant emotionality } \\
\text { Range: } 1-5\end{array}$ & $2.20(0.64)$ & $2.19(.66)$ & $2.21(.64)$ & 0.13 & 196 & .90 \\
\hline $\begin{array}{l}\text { Infant night waking } \\
\text { Range: } 0-2\end{array}$ & $0.76(0.57)$ & $.78(.58)$ & $.74(.57)$ & -0.39 & 196 & .70 \\
\hline \multicolumn{7}{|l|}{ Toddler outcomes } \\
\hline $\begin{array}{l}\text { Internalizing problems } \\
\text { Range: } 0-72\end{array}$ & $6.62(4.13)$ & $6.81(3.67)$ & $6.41(4.59)$ & -0.67 & 196 & .50 \\
\hline $\begin{array}{l}\text { Externalizing } \\
\text { problems } \\
\text { Range: } 0-48\end{array}$ & $12.71(6.12)$ & $13.43(6.41)$ & $11.91(5.73)$ & -1.76 & 196 & .08 \\
\hline
\end{tabular}


strated that, in the single-group model $(N=198)$, only infant emotionality positively predicted toddler problem behaviors $(\beta=.26, t=3.00)$. We then ran a two-group model to test moderation by child sex. Overall, the twogroup model demonstrated good fit with the data $\left(\chi^{2}=14.19, \mathrm{df}=12\right.$, $p=0.29 ;$ RMSEA $=.04 ;$ CFI $=.99)$, and significantly worsened $(p<.05)$ based on the chi-square difference, referencing the chi-square distribution table, when all paths were constrained between groups $\left(\chi^{2}=74.59\right.$, $\mathrm{df}=51$ ). This finding suggests there are between-group sex differences to explore further.

In the freely estimated two-group model, we found that, for boys (Figure 2), only maternal PTSD symptoms $(\beta=.26, t=1.99)$ significantly predicted toddler problems with a medium effect size. For girls (Figure 3), infant emotionality $(\beta=.37, t=3.32)$ and night waking $(\beta=.25, t=2.38)$ positively predicted toddler problems, both with medium effect sizes (Cohen, 1988).

TABLE 2

Correlations Among Maternal and Infant Predictors and Toddlers' Behavior Problems

$(N=198)$

\begin{tabular}{|c|c|c|c|c|c|c|c|}
\hline $\begin{array}{l}\text { Predictor and } \\
\text { Outcome Variables }\end{array}$ & 1. & 2. & 3. & 4. & 5. & 6. & 7. \\
\hline $\begin{array}{l}\text { 1. Maternal Child } \\
\text { Maltreatment }\end{array}$ & - & & & & & & \\
\hline $\begin{array}{l}\text { 2. Maternal PTSD } \\
\text { Symptoms }\end{array}$ & $.512 * *$ & - & & & & & \\
\hline $\begin{array}{l}\text { 3. Maternal } \\
\text { Depression } \\
\text { Symptoms }\end{array}$ & $.388 * *$ & $.584 * *$ & - & & & & \\
\hline $\begin{array}{l}\text { 4. Observed } \\
\text { Parenting } \\
\text { Engagement }\end{array}$ & -.071 & -.020 & $-.146^{*}$ & - & & & \\
\hline $\begin{array}{l}\text { 5. Cumulative } \\
\text { Demographic Risk }\end{array}$ & .077 & .011 & .098 & $-.417 * *$ & - & & \\
\hline $\begin{array}{l}\text { 6. Infant } \\
\text { Emotionality }\end{array}$ & .003 & .136 & $.281 * *$ & -.058 & .027 & & \\
\hline $\begin{array}{l}\text { 7. Infant Night } \\
\text { Waking }\end{array}$ & .058 & .067 & .015 & .065 & -.128 & .088 & \\
\hline $\begin{array}{l}\text { 8. Toddler Summed } \\
\text { Internalizing } \\
\text { and Externalizing } \\
\text { Behavior Problems }\end{array}$ & $.186^{* *}$ & $.187 * *$ & $.195 * *$ & $-.142^{*}$ & .060 & $.262^{* *}$ & .134 \\
\hline
\end{tabular}

Note. ${ }^{* *} p<.01,{ }^{*} p<.05$. 
To test moderation, we systematically constrained, one at a time, each direct path between an infancy predictor and the toddler outcomes to be equal between groups and evaluated the chi-square differences between the constrained models and the freely estimated two-group model based on the change in degrees of freedom, referencing the chi-square distribution table. Results demonstrated significant $(p<.05)$ between-group differences for the association between PTSD and toddler outcomes. Although child night waking and infant emotionality were significant for girls and not for boys, these variables were not significantly different by child sex in the between-group analyses at the level of $p<.05$. However, there were differences between boys and girls in the relationship between night waking and toddler problems at the trend level $(p<.10)$.

\section{DISCUSSION}

The primary aim of the current study was to evaluate child sex as a moderator of the transmission of risks in a sample of high-risk mothers. As hypothesized, results revealed a different pattern of results for boys and girls. For boys, higher maternal PTSD symptoms assessed at 6 months

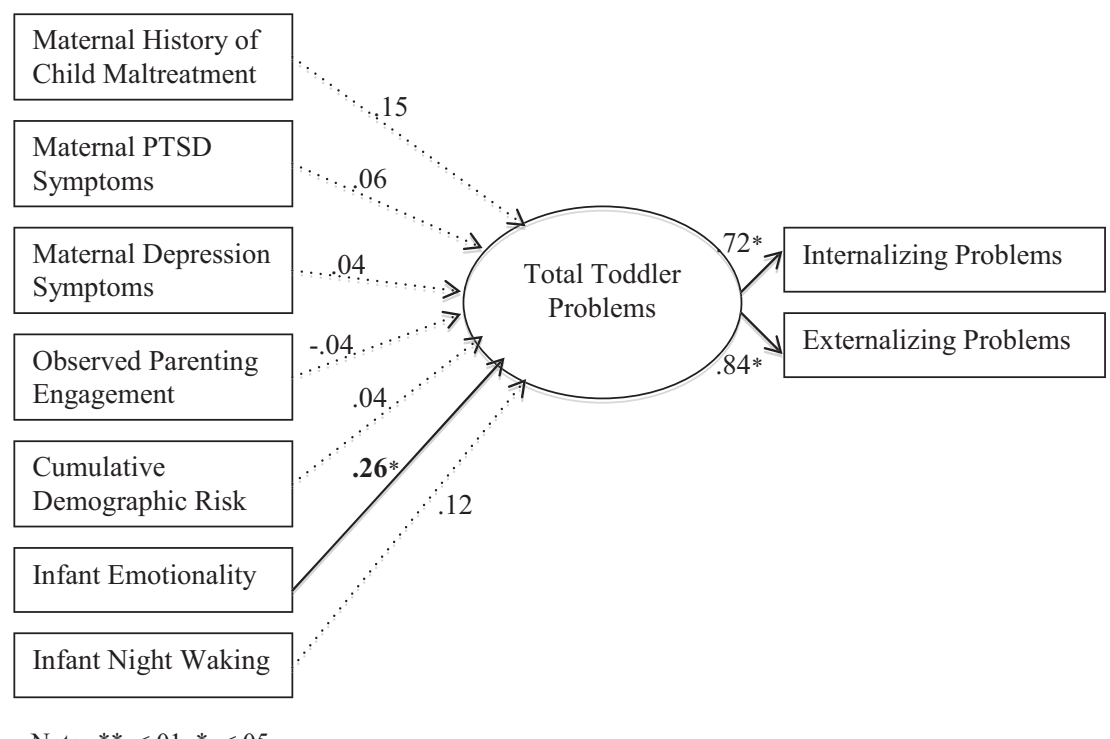

Note: ${ }^{* *} p<.01,{ }^{*} p<.05$

Figure 1 Empirical results from predictors of toddler behaviors full model. Note: $* * p<.01, * p<.05$. 
postpartum significantly predicted higher total behavior problem scores at 18 months. For girls, infant regulation factors (infant emotionality and night waking) assessed at 6 months postpartum predicted higher total problem behaviors scores at 18 months. Only the predictiveness of maternal PTSD symptoms on toddler total problems differed significantly for boys compared to girls.

Our results are both consistent and inconsistent with other findings examining problems behaviors in toddlerhood. Similar to the current findings, Shaw and Vondra (1995) and Carter et al. (2001) also found that boys' problems in early childhood were predicted by maternal psychopathology during infancy. However, in these prior studies, it was maternal depression specifically that affected boys more than girls, as PTSD was not evaluated. Our nonsignificant finding regarding maternal depression may be a consequence of our sample recruitment strategies. These women were over-recruited for a history of childhood trauma, and therefore, more likely than women in unselected community samples to have PTSD, which may have overshadowed any effect of depressive symptoms in the sample. It is notable that, in the regressions conducted on the subset of our sample without imputed data, both maternal depression and PTSD symptoms were each significant predictors of boys' (but not girls') behavior

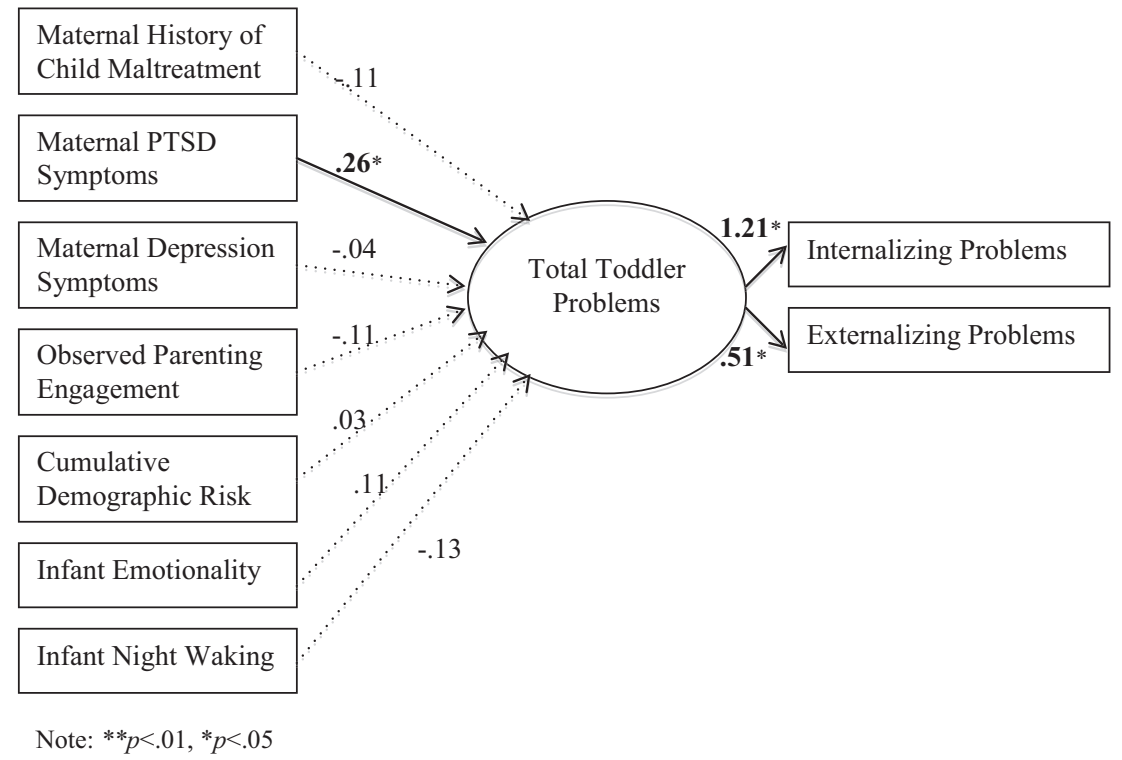

Figure 2 Empirical results from predictors of toddler behaviors for boys. Note: ${ }^{* *} p<.01, * p<.05$. 


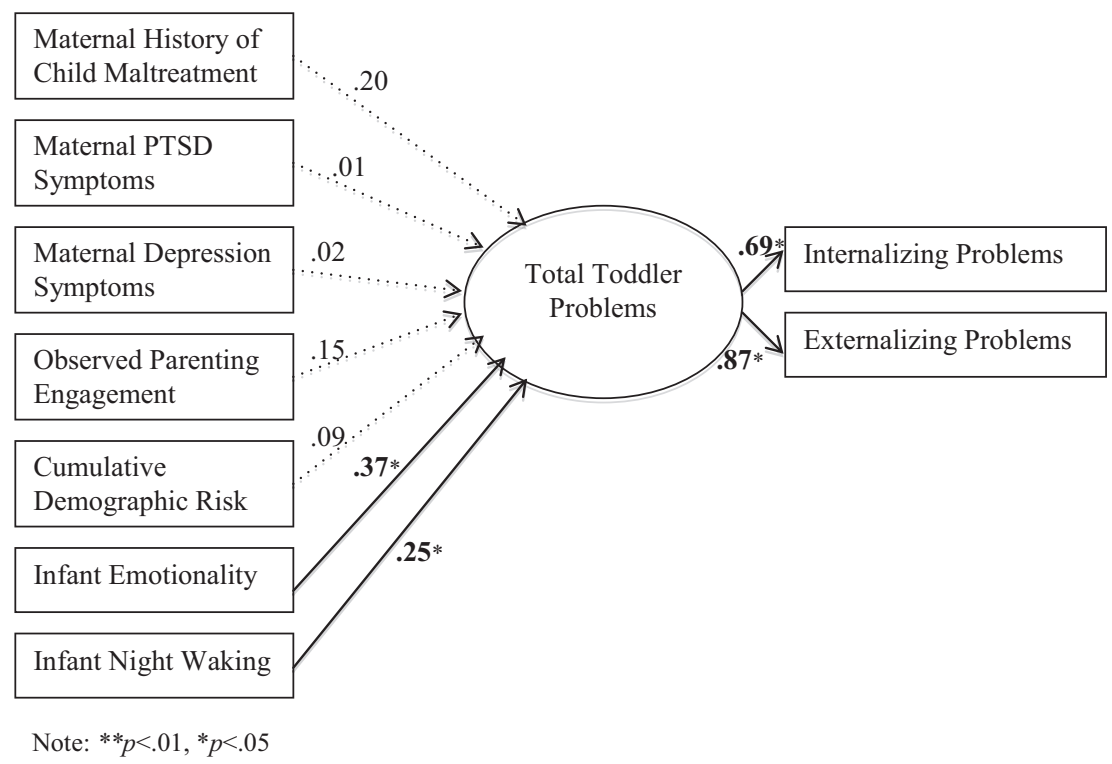

Figure 3 Empirical results from predictors of toddler behaviors for girls. Note: ${ }^{* *} p<.01, * p<.05$.

problems. However, in the SEM analyses based on the larger sample with imputed data, PTSD symptoms uniquely predicted toddlers' behavior problems.

The results of the SEM analyses also revealed no significant sex differences in the association between the quality of parenting engagement during mother-infant interaction at 6 months and toddlers' behavior problems. This null finding is consistent with the null finding of harsh discipline on problem behaviors in older children reported by McKee et al. (2007), but inconsistent with findings in other studies evaluating more general indices of parenting quality and toddlers' outcome (Carter et al., 2001; Shaw \& Vondra, 1995). Shaw and Vondra (1995) found that low maternal involvement negatively affected boys' (but not girls') outcomes. These results are similar to our regression results based on the smaller sample without imputed data, which showed a significant, negative association between parenting engagement and boys' (but not girls') problem behaviors. These latter findings are consistent with the theory that boys are more vulnerable to postpartum maternal risk (psychopathology and suboptimal parenting). Contrasting results, however, were reported by Carter et al. (2001), who found that parenting behaviors were correlated with problem behaviors for girls only. We speculate that the inconsistent 
findings in this literature may stem, in part from methodological differences in sample characteristics, sample size, age at assessment, the use of different assessments, and variations in statistical methods. The mixed results regarding sex differences in the association between early caregiving characteristics and behavior on children's later adjustment merit further research and replication in larger, more diverse samples.

Finally, maternal-rated difficult temperament in infancy is a known predictor of later child behavior problems in general (Sanson et al., 1993) and, in at least one prior study, for girls uniquely when models are separated by child sex (Shaw \& Vondra, 1995). Similarly, in the current study, maternal-rated infant negative emotionality was predictive of toddler behavior problems in the overall sample and in girls only when the model was separated by child sex. This suggests that the effect of child negative temperament on later adjustment is mainly driven by the results in the female subsample. Although emotionality and sleep regulation were significantly predictive for girls' problem behaviors only, they were not statistically different for girls compared to boys in the combined sample. Thus, we cannot conclude that child sex is a moderator, but future studies should continue to examine sex differences in the effect sizes of infant temperament on subsequent child adjustment.

The lack of significant findings for child sex as a moderator of other maternal risk factors (depression, history of childhood maltreatment, and postpartum caregiving) in the current SEM analyses may indicate there is no difference between male and female susceptibility for these predictors. However, maternal PTSD was the single variable that significantly differed between the male and female models of risk transmission in this model; thus, we entertain two possibilities to explain this finding: (1) boys are more susceptible to maternal psychopathology (specifically, PTSD), which may shape their developmental adaptation over time, and/or (2) mothers with psychopathology view their boy and girl infants differently and overreport behavior problems in boys. These possibilities are not necessarily mutually exclusive.

The reasons for this gendered differential susceptibility are not fully understood. There is some evidence that boys at this early age may be less developmentally mature than girls, (Keenan \& Shaw, 1997), less capable of self-regulating negative emotions (Kochanska et al., 2001), and thus more susceptible to the negative effects of caregiving casualty (as indexed by maternal PTSD). Some have argued that this sex-based differential maturation and vulnerability arises in fetal development possibly influenced by epigenetic mechanisms leading to differential cell growth and steroid hormone receptor distribution in the fetal brain for males and females (Hodes, 2013). For example, male rat pups exposed to prenatal 
stress exhibit learning deficits postpartum, whereas female pups show unchanged or even improved learning performance and stress coping strategies compared to controls (Mueller \& Bale, 2007). These investigators suggest differential susceptibility may arise from differential rates of developmental maturation in males and females, and differences in how gonadal hormones in each sex are linked to learning performance. Lyon and Gadisseux (1991) hypothesized that exposure to higher testosterone levels in utero may lead to more neuronal cell death and slower development of the brain (Lyon \& Gadisseux, 1991), which in turn, may prolong the period during which males are vulnerable to early environmental insult (Lyon \& Gadisseux, 1991) such as poor maternal care (Kochanska et al., 2001; Robinson, Little, \& Biringen, 1993). Animal work (Hodes, 2013) has also shown how high-quality maternal care can epigenetically alter methylation levels of receptors relevant to stress regulation (i.e., glucocorticoid receptors regulating cortisol stress hormone release) in critical brain regions (i.e., hippocampus), which has been found to alter stress sensitivity in adult male rodent offspring (Weaver et al., 2004). Whereas no corresponding epigenetic study in humans has yet confirmed this hypothesis, at least from animal work, it appears that environmental factors may act epigenetically in multiple brain regions to alter sex-specific sensitivity to stress, and shape developmental adaptation.

In humans, social learning over time may interact with a-priori biological vulnerability and potentiate sex differences in risk trajectories. For example, Carter et al. (2001) speculate that young boys may have less adaptive social strategies and therefore are less apt to engage a mother who may exhibit intermittent unavailability known to be characteristic of women with depression or PTSD (Moehler, Biringen, \& Poustka, 2007; Trapolini, Ungerer, \& McMahon, 2008). Boys then might fall back on problematic behaviors to engage their mothers under these circumstances (Carter et al., 2001; Weinberg, Olson, Beeghly, \& Tronick, 2006). Girls, on the other hand, have less exposure to prenatal testosterone, exhibit faster prenatal brain development, and their mothers may have stricter expectations for their behavior, which may help them to develop regulatory capabilities earlier than boys.

Maternal perception bias may also contribute to the specific sex differences identified in the current analyses. Research shows that parents perceive their male and female infants differently even hours after birth (Rubin, Provenzano, \& Luria, 1974). Moreover, gender role preconceptions might be magnified when mothers report on their infant's problems, while they are currently experiencing a maladaptive psychological state (i.e., PTSD). Although some studies report that mothers with psychopathology over-report their child's behavior problems (Chilcoat \& Breslau, 
1997), to our knowledge, only Shaw and Vondra (1995) and Hammen et al. (2012) have speculated that child sex influences the relationship between maternal depression and mothers' reports of their child's behavior problems. The current analyses reveal that mothers with more PTSD symptoms rate their sons (but not their daughters) as having more problems. Perhaps for mothers with postpartum PTSD, their toddler sons' more active behaviors are perceived as frightening and/or hostile (Briere, 1992), which may be especially salient if those mothers were maltreated by a male figure (Lieberman, 1996).

Whether sex differences surrounding maternal PTSD are originally conceived through developmental susceptibility or via maternal perception biases, data from transactional longitudinal models tell us that sex differences in maternal-reported child problem behaviors eventually become reality for children as they grow older (Fiese \& Sameroff, 1989).

This study is not without limitations. First, over half of the women in this sample experienced relatively low demographic risk profiles, which restricts generalizability of findings to higher-risk samples. Moreover, those with higher levels of demographic risk had higher rates of attrition throughout the study, which also restricts generalizability. Additionally, the restricted range of negative parenting behaviors is problematic, especially the low levels of abusive and frightening behaviors in this sample may also pose a limitation to detect effects for high-risk parenting behaviors on sex-specific child behavioral problems. Another limitation in this study is shared method variance. With the exception of observed ratings of maternal engagement with the infant during social interaction at 6 months, all measures were derived from maternal report. In future research, evaluation of additional measures such as objective assessments of children's functioning, or the use of multiple informants regarding infants' regulatory capacity and behavior problems, could be helpful in clarifying whether infant susceptibility or maternal reporting is responsible for sex differences in children's developmental trajectories. Finally, although our sample size likely exceeds necessary lower bounds, the findings should be replicated in larger samples to confirm model fit, as the sensitivity of the chi-square statistic increases with sample size (Barrett, 2007).

In the current study, we did not evaluate several potentially confounding variables that could also explain additional model variance and should be measured in subsequent studies as they all contribute to maternal postpartum mental health. Such confounding variables include maternal mental health treatment and medication use, maternal comorbidities such as substance abuse, maternal characteristics such as gravidity and parity, and/or stressful events occurring throughout the first postpartum years. Furthermore, due to sample size and diversity restrictions, we assessed 
demographic risk as an index, but did not fully evaluate potential ethnic/ racial differences or poverty as distinct risk variables. Additionally, with a larger sample size, it would be possible to analyze differential impact of type of maltreatment (abuse versus neglect) on parenting practices. As the current study did not control for 18-month maternal self-report of psychopathology; subsequent studies may benefit from analyses disentangling the unique effects of maternal depression at different developmental periods. We chose not to covary 18-month maternal-reported psychopathology due to its strong correlation with 6-month maternal-reported psychopathology and the likelihood that inclusion of the 18-month report would represent an over-control. Furthermore, our analyses modeled direct effects of postpartum risk factors on child risk only; mechanistic, indirect pathway analyses had to be omitted due to power issues; these should be explored in future research in larger samples (Goodman et al., 2011). Although sample size restricted our ability to evaluate these variables in the present study, future research would do well to investigate these additional variables in their analytic models.

The findings from this study have practical implications. From a clinical perspective, our PTSD by child gender finding highlights the potential need of clinicians and intervention specialists to have differential targets for boys and girls when delivering prevention or intervention services in at-risk families. Specifically, when considering intervention programs for mothers with postpartum PTSD, a specific focus should be how mothers perceive their sons and whether this is associated with parenting distortions, which in turn, may impact how mothers interact with their sons, paving the way for aberrant developmental pathways. In contrast, focusing on temperament and sleep regulation may be especially relevant when intervening in clinical contexts with female infants. However, the current study also has several null maternal risks by gender interactions and thus results should be interpreted with caution until they can be replicated in larger studies. Research on sex-specific developmental risk has the potential to be integrated into our clinical understanding of childhood psychopathology and may guide the development of gender-sensitive intervention strategies that aim to support child resiliency in the context of environmental risk.

\section{REFERENCES}

Achenbach, T. M., \& Rescorla, L. A. (2000). Manual for the ASEBA preschool formpreschool forms \& profiles. Burlington, VT: University of Vermont, Research Center for Children, Youth, and Families. 
Acock, A. C. (2005). Working with missing values. Journal of Marriage and Family, 67, $1012-1028$.

Al-Turkait, F. A., \& Ohaeri, J. U. (2008). Prevalence and correlates of posttraumatic stress disorder among Kuwaiti military men according to level of involvement in the first Gulf War. Depression and Anxiety, 25, 932-941.

Anders, T. F., \& Keener, M. (1985). Developmental course of nighttime sleep-wake patterns in full-term and premature infants during the first year of life. I. Sleep, 8, 173-192.

Armstrong, M., Birnie-Lefcovitch, S., \& Ungar, M. (2005). Pathways between social support, family well being, quality of parenting, and child resilience: What we know. Journal of Child and Family Studies, 14, 269-281.

Bagner, D. M., Pettit, J. W., Lewinsohn, P. M., \& Seeley, J. R. (2010). Effect of maternal depression on child behavior: A sensitive period? Journal of the American Academy of Child \& Adolescent Psychiatry, 49, 699-707.

Barrett, P. (2007). Structural equation modelling: Adjudging model fit. Personality and Individual Differences, 42, 815-824.

Beardslee, W. R., Gladstone, T. R. G., \& O’Connor, E. E. (2011). Transmission and prevention of mood disorders among children of affectively ill parents: A review. Journal of the American Academy of Child and Adolescent Psychiatry, 50, 1098-1109.

Beck, C. T., \& Gable, R. K. (2000). Postpartum depression screening scale: Development and psychometric testing. Nursing Research, 49, 272-282.

Beeghly, M. (2006). Translational research on early language development: current challenges and future directions. Development and Psychopathology, 18, 737-757.

Bernstein, D. P., \& Fink, L. (1998). Childhood trauma questionnaire: A retrospective selfreport. Harcourt Brace \& Company.

Bifulco, A., Moran, P. M., Ball, C., Jacobs, C., Baines, R., Bunn, A., \& Cavagin, J. (2002). Childhood adversity, parental vulnerability and disorder: Examining inter-generational transmission of risk. Journal of Child Psychology and Psychiatry, and Allied Disciplines, 43, 1075-1086.

Blatt-Eisengart, I., Drabick, D. A. G., Monahan, K. C., \& Steinberg, L. (2009). Sex differences in the longitudinal relations among family risk factors and childhood externalizing symptoms. Developmental Psychology, 45, 491-502.

Bocknek, E. L., Brophy-Herb, H. E., \& Banerjee, M. (2009). Effects of parental supportiveness on toddlers' emotion regulation over the first three years of life in a low-income African American sample. Infant Mental Health Journal, 30, 452-476.

Boomsma, A. (1983). On the robustness of LISREL (maximum likelihood estimation) against small sample size and nonnormality. Unpublished Doctoral Dissertation, University of Groningen, Groningen, Netherlands.

Bouchard, C., Trudeau, N., Sutton, A., Boudreault, M.-C., \& Deneault, J. (2009). Gender differences in language development in French Canadian children between 8 and 30 months of age. Applied Psycholinguistics, 30(04), 685-707.

Briere, J. N. (1992). Child abuse trauma: Theory and treatment of the lasting effects. Sage: Newbury Park, CA.

Brody, G. H., Chen, Y.-f., Murry, V. M., Ge, X., Simons, R. L., Gibbons, F. X., ... \& Cutrona, C. (2006). Perceived discrimination and the adjustment of African American youths: A five-year longitudinal analysis with contextual moderation effects. Child Development, 77, 1170-1189.

Buist, A. (1998). Childhood abuse, postpartum depression and parenting difficulties: A literature review of associations. The Australian and New Zealand Journal of Psychiatry, 32, 370-378. 
Buss, A. H., \& Plomin, R. (1975). A temperament survey of personality development. New York: Wiley.

Capaldi, D. M., Pears, K. C., Kerr, D. C. R., Owen, L. D., \& Kim, H. K. (2012). Growth in externalizing and internalizing problems in childhood: A prospective study of psychopathology across three generations. Child Development, 83, 1945-1959.

Carter, A. S., Garrity-Rokous, F. E., Chazan-Cohen, R., Little, C., \& Briggs-Gowan, M. J. (2001). Maternal depression and comorbidity: Predicting early parenting, attachment security, and toddler social-emotional problems and competencies. Journal of the American Academy of Child and Adolescent Psychiatry, 40(1), 18-26.

Causadias, J. M., Salvatore, J. E., \& Sroufe, L. A. (2012). Early patterns of self-regulation as risk and promotive factors in development: A longitudinal study from childhood to adulthood in a high-risk sample. International Journal of Behavioral Development, 36, 293-302.

Champagne, F. A., \& Curley, J. P. (2009). Epigenetic mechanisms mediating the long-term effects of maternal care on development. Neuroscience and Biobehavioral Reviews, 33, 593600 .

Chilcoat, H. D., \& Breslau, N. (1997). Does psychiatric history bias mothers' reports? An application of a new analytic approach. Journal of the American Academy of Child and Adolescent Psychiatry, 36, 971-979.

Chung, W. C. J., \& Auger, A. P. (2013). Gender differences in neurodevelopment and epigenetics. Pfü̈gers Archiv: European Journal of Physiology, 465, 573-584.

Cohen, J. (1988). Statistical power analysis for the behavioral sciences. Routledge Academic. New York, NY.

Cortese, S., Faraone, S. V., Konofal, E., \& Lecendreux, M. (2009). Sleep in children with attention-deficit/hyperactivity disorder: Meta-analysis of subjective and objective studies. Journal of the American Academy of Child and Adolescent Psychiatry, 48, 894-908.

Dayton, C. J., Levendosky, A. A., Davidson, W. S., \& Bogat, G. A. (2010). The child as held in the mind of the mother: The influence of prenatal maternal representations on parenting behaviors. Infant Mental Health Journal, 31(2), 220-241.

Davies, P. L., Segalowitz, S. J., \& Gavin, W. J. (2004). Development of response-monitoring ERPs in 7- to 25-year-olds. Developmental Neuropsychology, 25, 355-376.

Dempster, A. P., Laird, N. M., \& Rubin, D. B. (1977). Maximum likelihood from incomplete data via the EM algorithm. Journal of the Royal Statistical Society. Series B (Methodologi(cal), 1-38.

DiLalla, L. F., Mullineaux, P. Y., \& Biebl, S. J. W. (2012). Social-emotional development through a behavior genetics lens: Infancy through preschool. Advances in Child Development and Behavior, 42, 153-196.

Earls, L., Muzik, M., \& Beeghly, M. (2009). Maternal and infant behavior coding manual. Unpublished manuscript, Department of Psychiatry, University of Michigan, Ann Arbor, MI.

Easterbrooks, M. A., Bureau, J.-F., \& Lyons-Ruth, K. (2012). Developmental correlates and predictors of emotional availability in mother-child interaction: A longitudinal study from infancy to middle childhood. Development and Psychopathology, 24(1), 65-78.

Essex, M. J., Klein, M. H., Cho, E., \& Kalin, N. H. (2002). Maternal stress beginning in infancy may sensitize children to later stress exposure: Effects on cortisol and behavior. Biological Psychiatry, 52, 776-784.

Fabrigar, L., \& Wegener, D. (2011). Exploratory factor analysis, New York, NY: Oxford.

Feldman, R. (1998). Coding interactive behaviour manual. Israel: Bar-llan University.

Fiese, B. H., \& Sameroff, A. J. (1989). Family context in pediatric psychology: A transactional perspective. Journal of Pediatric Psychology, 14, 293-314. 
Forbes, E. E., Bertocci, M. A., Gregory, A. M., Ryan, N. D., Axelson, D. A., Birmaher, B., \& Dahl, R. E. (2008). Objective sleep in pediatric anxiety disorders and major depressive disorder. Journal of the American Academy of Child and Adolescent Psychiatry, 47, 148-155.

Fox, N. A. (2004). Temperament and early experience form social behavior. Annals of the New York Academy of Sciences, 1038, 171-178.

Gartstein, M. A., Putnam, S. P., \& Rothbart, M. K. (2012). Etiology of preschool behavior problems: Contributions of temperament attributes in early childhood. Infant Mental Health Journal, 33(2), 197-211.

Gebring, D. W., \& Anderson, J. C. (1985). The effects of sampling error and model characteristics on parameter estimation for maximum likelihood confirmatory factor analysis. Multivariate Behavioral Research, 20, 255-271.

Glover, V. (2011). Annual Research Review: Prenatal stress and the origins of psychopathology: An evolutionary perspective. Journal of Child Psychology and Psychiatry, and Allied Disciplines, 52, 356-367.

Goodlin-Jones, B. L., Burnham, M. M., Gaylor, E., \& Anders, T. F. (2001). Night waking, sleep-wake organization, and self-soothing in the first year of life. Journal of Developmental and Behavioral Pediatrics: JDBP, 22, 226-233.

Goodman, S. H., Rouse, M. H., Connell, A. M., Broth, M. R., Hall, C. M., \& Heyward, D. (2011). Maternal depression and child psychopathology: A meta-analytic review. Clinical Child and Family Psychology Review, 14(1), 1-27.

Graham, J. W. (2012). Missing Data: Analysis and Design. Springer Science. New York, NY. 47-69.

Gregory, A. M., \& Sadeh, A. (2012). Sleep, emotional and behavioral difficulties in children and adolescents. Sleep Medicine Reviews, 16, 129-136.

Hairston, I. S., Waxler, E., Seng, J. S., Fezzey, A. G., Rosenblum, K. L., \& Muzik, M. (2011). The role of infant sleep in intergenerational transmission of trauma. Sleep, 34, $1373-1383$.

Hammen, C. (2005). Stress and depression. Annual Review of Clinical Psychology, 1(1), 293319.

Hammen, C., Hazel, N. A., Brennan, P. A., \& Najman, J. (2012). Intergenerational transmission and continuity of stress and depression: Depressed women and their offspring in 20 years of follow-up. Psychological Medicine, 42, 931-942.

Harold, G. T., Rice, F., Hay, D. F., Boivin, J., van den Bree, M., \& Thapar, A. (2011). Familial transmission of depression and antisocial behavior symptoms: Disentangling the contribution of inherited and environmental factors and testing the mediating role of parenting. Psychological Medicine, 41, 1175-1185.

Herrenkohl, T. I., Hong, S., Klika, J. B., Herrenkohl, R. C., \& Russo, M. J. (2012). Developmental impacts of child abuse and neglect related to adult mental health, substance use, and physical health. Journal of Family Violence, 28(2), 1-9.

Hodes, G. E. (2013). Sex, stress, and epigenetics: Regulation of behavior in animal models of mood disorders. Biology of Sex Differences, 4(1), 1.

Hofferth, S. L., Pleck, J. H., \& Vesely, C. K. (2012). The transmission of parenting from fathers to sons. Parenting, Science and Practice, 12, 282-305.

Hu, L., \& Bentler, P. M. (1999). Cutoff criteria for fit indexes in covariance structure analysis: Conventional criteria versus new alternatives. Structural Equation Modeling: A Multidisciplinary Journal, 6(1), 1-55.

Iacobucci, D. (2010). Structural Equation Modeling: Fit Indices, sample size, and advanced topics. Journal of Consumer Technology, 20, 90-98.

Keenan, K., \& Shaw, D. (1997). Developmental and social influences on young girls' early problem behavior. Psychological Bulletin, 121(1), 95-113. 
Keiley, M. K., Lofthouse, N., Bates, J. E., Dodge, K. A., \& Pettit, G. S. (2003). Differential risks of covarying and pure components in mother and teacher reports of externalizing and internalizing behavior across ages 5 to 14. Journal of Abnormal Child Psychology: An Official Publication of the International Society for Research in Child and Adolescent Psychopathology, 31, 267-283.

Kochanska, G., Coy, K. C., \& Murray, K. T. (2001). The development of self-regulation in the first four years of life. Child Development, 72, 1091-1111.

Kovacs, M., Devlin, B., Pollock, M., Richards, C., \& Mukerji, P. (1997). A controlled family history study of childhood-onset depressive disorder. Archives of General Psychiatry, 54, 613-623.

Lieberman, A. F. (1996). Aggression and sexuality in relation to toddler attachment: Implications for the caregiving system. Infant Mental Health Journal, 17, 276-292.

Loeber, R., Hipwell, A., Battista, D., Sembower, M., \& Stouthamer-Loeber, M. (2009). Intergenerational transmission of multiple problem behaviors: Prospective relationships between mothers and daughters. Journal of Abnormal Child Psychology, 37, 1035-1048.

Lunkenheimer, E. S., Olson, S. L., Hollenstein, T., Sameroff, A. J., \& Winter, C. (2011). Dyadic flexibility and positive affect in parent-child coregulation and the development of child behavior problems. Development and Psychopathology, 23(2), 577-591.

Lyon, G., \& Gadisseux, J.-F. (1991). Structural abnormalities of the brain in developmental disorders. In M. Rutter, \& P. Casaer (Eds.), Biological risk factors for psychosocial disorders (pp. 1-19). New York, NY: Cambridge University Press.

MacCallum, R. C., \& Austin, J. T. (2000). Applications of structural equation modeling in psychological research. Annual Review of Psychology, 51, 201-226.

Martel, M. M., Klump, K., Nigg, J. T., Breedlove, S. M., \& Sisk, C. L. (2009). Potential hormonal mechanisms of attention-deficit/hyperactivity disorder and major depressive disorder: A new perspective. Hormones and Behavior, 55, 465-479.

Martinez-Torteya, C., Dayton, C., Beeghly, M., McGinnis, E., Broderick, A., Rosenblum, K. L., \& Muzik, M. (2013). Maternal parenting predicts infant biobehavioral regulation among women with a history of childhood maltreatment. Developmental Psychopathology, 26(2), 379-392.

Mathiesen, K. S., Sanson, A., Stoolmiller, M., \& Karevold, E. (2009). The nature and predictors of undercontrolled and internalizing problem trajectories across early childhood. Journal of Abnormal Child Psychology: An Official Publication of the International Society for Research in Child and Adolescent Psychopathology, 37, 209-222.

McKee, L., Roland, E., Coffelt, N., Olson, A., Forehand, R., Massari, C., ... Zens, M. (2007). Harsh discipline and child problem behaviors: The roles of positive parenting and gender. Journal of Family Violence, 22, 187-196.

McLearn, K. T., Minkovitz, C. S., Strobino, D. M., Marks, E., \& Hou, W. (2006). The timing of maternal depressive symptoms and mothers' parenting practices with young children: Implications for pediatric practice. Pediatrics, 118(1), e174-e182.

Miner, J. L., \& Clarke-Stewart, K. A. (2008). Trajectories of externalizing behavior from age 2 to age 9: Relations with gender, temperament, ethnicity, parenting, and rater. Developmental Psychology, 44, 771-786.

Moehler, E., Biringen, Z., \& Poustka, L. (2007). Emotional availability in a sample of mothers with a history of abuse. The American Journal of Orthopsychiatry, 77, 624-628.

Mueller, B. R., \& Bale, T. L. (2007). Early prenatal stress impact on coping strategies and learning performance is sex dependent. Physiology \& Behavior, 91(1), 55-65.

Muzik, M., Bocknek, E. L., Broderick, A., Richardson, P., Rosenblum, K. L., Thelen, K., \& Seng, J. S. (2013). Mother-infant bonding impairment across the first 6 months postpar- 
tum: The primacy of psychopathology in women with childhood abuse and neglect histories. Archives of Women's Mental Health, 16(1), 29-38.

Newman, D. A. (2003). Longitudinal modeling with randomly and systematically missing data: A simulation of ad hoc, maximum likelihood, and multiple imputation techniques. Organizational Research Methods, 6, 328-362.

Nigg, J. T., \& Goldsmith, H. H. (1998). Developmental psychopathology, personality, and temperament: Reflections on recent behavioral genetics research. Human Biology, 70, 387412.

Petterson, S. M., \& Albers, A. B. (2001). Effects of poverty and maternal depression on early child development. Child Development, 72, 1794-1813.

Rende, R. D. (1993). Longitudinal relations between temperament traits and behavioral syndromes in middle childhood. Journal of the American Academy of Child \& Adolescent Psychiatry, 32, 287-290.

Resnick, H. S., Kilpatrick, D. G., Dansky, B. S., Saunders, B. E., \& Best, C. L. (1993). Prevalence of civilian trauma and posttraumatic stress disorder in a representative national sample of women. Journal of Consulting and Clinical Psychology, 61, 984-991.

Robinson, J., Little, C., \& Biringen, Z. (1993). Emotional communication in mother-toddler relationships: Evidence for early gender differentiation. Merrill-Palmer Quarterly, 39(4), 496-517.

Rubin, J. Z., Provenzano, F. J., \& Luria, Z. (1974). The eye of the beholder: Parent's views on sex of newborns. American Journal of Orthopsychiatry, 44, 512-519.

Sameroff, A., Seifer, R., \& McDonough, S. (2004). Contextual contributors to the assessment of infant mental health. In DelCarmen-Wiggins, Editor \& Carter (Editor), Handbook of infant, toddler, and preschool mental health assessment (pp. 61-76). New York, NY: Oxford University Press.

Sanson, A., Smart, D., Prior, M., \& Oberklaid, F. (1993). Precursors of hyperactivity and aggression. Journal of the American Academy of Child and Adolescent Psychiatry, 32, 12071216.

Schafer, J. L., \& Graham, J. W. (2002). Missing data: Our view of the state of the art. Psychological Methods, 7, 147-177.

Schwichtenberg, A. J., \& Goodlin-Jones, B. (2010). Causes and correlates of frequent night awakenings in early childhood. International Review of Neurobiology, 93, 177-191.

Seifer, R., Dickstein, S., Spirito, A., \& Owens-Stively, J. (1996). Parent reports about sleep habits of infants and toddlers. Infant Behavior and Development, 19, 2.

Selimbasic, Z., Sinanovic, O., \& Avdibegovic, E. (2012). Psychosocial problems among children of parents with posttraumatic stress disorder. Medicinski Arhiv, 66, 304-308.

Seng, J. S., Low, L. M. K., Sperlich, M., Ronis, D. L., \& Liberzon, I. (2009). Prevalence, trauma history, and risk for posttraumatic stress disorder among nulliparous women in maternity care. Obstetrics and Gynecology, 114, 839-847.

Serbin, L. A., \& Karp, J. (2004). The intergenerational transfer of psychosocial risk: Mediators of vulnerability and resilience. Annual Review of Psychology, 55, 333-363.

Shaw, D. S., \& Vondra, J. I. (1995). Infant attachment security and maternal predictors of early behavior problems: A longitudinal study of low-income families. Journal of Abnormal Child Psychology, 23, 335-357.

Spruyt, K., Aitken, R. J., So, K., Charlton, M., Adamson, T. M., \& Horne, R. S. C. (2008). Relationship between sleep/wake patterns, temperament and overall development in term infants over the first year of life. Early Human Development, 84, 289-296.

Tanaka, J. S. (1987). "How big is big enough?": Sample size and goodness of fit in structural equation models with latent variables. Child Development, 58(1), 134-146. 
Tomarken, A. J., \& Waller, N. G. (2005). Structural equation modeling: Strengths, limitations, and misconceptions. Annual Review of Clinical Psychology, 1, 31-65.

Trapolini, T., Ungerer, J. A., \& McMahon, C. A. (2008). Maternal depression: Relations with maternal caregiving representations and emotional availability during the preschool years. Attachment \& Human Development, 10(1), 73-90.

Valentino, K., Berkowitz, S., \& Stover, C. S. (2010). Parenting behaviors and posttraumatic symptoms in relation to children's symptomatology following a traumatic event. Journal of Traumatic Stress, 23, 403-407.

Van Ee, E., Kleber, R. J., \& Mooren, T. T. M. (2012). War trauma lingers on: Associations between maternal posttraumatic stress disorder, parent-child interaction, and child development. Infant Mental Health Journal, 33, 459-468.

Wan, M. W., \& Green, J. (2009). The impact of maternal psychopathology on child-mother attachment. Archives of Women's Mental Health, 12, 123-134.

Weaver, I. C. G., Cervoni, N., Champagne, F. A., D’Alessio, A. C., Sharma, S., Seckl, J. R., ... Meaney, M. J. (2004). Epigenetic programming by maternal behavior. Nature Neuroscience, $7,847-854$.

Weinberg, M., Olson, K., Beeghly, M., \& Tronick, E. (2006). Making up is hard to do, especially for mothers with high levels of depressive symptoms and their infant sons. Journal of Child Psychology and Psychiatry, 47, 670-683.

Williams, L. R., Degnan, K. A., Perez-Edgar, K. E., Henderson, H. A., Rubin, K. H., Pine, D. S., ... Fox, N. A. (2009). Impact of behavioral inhibition and parenting style on internalizing and externalizing problems from early childhood through adolescence. Journal of Abnormal Child Psychology: An Official Publication of the International Society for Research in Child and Adolescent Psychopathology, 37, 1063-1075.

Yehuda, R., Halligan, S. L., \& Grossman, R. (2001). Childhood trauma and risk for PTSD: Relationship to intergenerational effects of trauma, parental PTSD, and cortisol excretion. Development and Psychopathology, 13, 733-753. 